\title{
Historia de la medicina: modelo holístico
}

History of medicine: holistic model

\author{
Stephanie Tapia-Pérez ${ }^{a *}$, Axel M. Reyna-Rivas ${ }^{a}$, Eddie E. Monroy-Ordoñez ${ }^{a}$
}

\begin{abstract}
:
The energy in balance, given by the body and the spirit as a unit, the Ayurveda (sanscrite word for life science) explains that this was revealed by divine beings which explains on many health-related views, such as the use of $d$ and medication, doing yoga, meditation until surgery.

Chakras this is a system of Buddhist beliefs, chakras are found in different regions of the body, but in specific places such as an organ but invisible, which is only measured by their energy, of which six are aligned in the spine ascending and one hovers out of the body between the genitals and the knees. If there was any blockage of energy then a physical or mental illness can occur, to treat from a therapeutic point of view you have to align the chakras; using special stones or songs, just like yoga helps maintain this flow of energy.

The four humors in the same way as chakras, should be kept in balance if you wanted to maintain health, which are black bile, yellow bile, blood and phlegm. The origins come from Mesopotamia or Egypt, the four humors are related, to the four elements water, earth and air. Humeral theory dealt with mental health and temperament in addition to physical well-being, the balance of humors or yin and yang was considered to be sufficient explanation of how the body worked or failed.
\end{abstract}

\section{Keywords:}

Chakras, ayurveda, divine beings four moods, black bile, yellow bile, blood and phlegm, mental health, yoga

\section{Resumen:}

La energía en equilibrio, está dado por el cuerpo y el espíritu como una unidad, la ayurveda (palabra sanscrita para ciencia de la vida) explica que esta fue revelada por seres divinos la cual explica sobre muchos puntos de vista relacionados con la salud, como el uso de medicamento, hacer yoga, meditación hasta la cirugía.

Chakras este es un sistema de creencias budistas, los chakras se encuentran en distintas regiones del cuerpo, pero en lugares específico como un órgano pero invisible, que solo se mide por su energía, de los cuales seis se encuentran alineados en la columna vertebral ascendentemente y uno se cierne fuera del cuerpo entre los genitales y las rodillas. Si existiera algún bloqueo de la energía entonces se puede producir una enfermedad física o mental, para tratar desde un punto de vista terapéutico se tiene que alinear los chakras; usando piedras especiales o canticos, al igual el yoga ayuda a mantener este flujo de energía.

Los cuatro humores de igual manera que los chakras, se debían de mantener en equilibrio si se quería mantener la salud, los cuales son bilis negra, bilis amarilla, sangre y flema. Los orígenes vienen de Mesopotamia o Egipto, los cuatro humores están relacionados, con los cuatro elementos agua, tierra y aire. La teoría humeral se ocupaba de la salud mental y el temperamento además del bienestar físico, se consideraba que el equilibrio de los humores o del yin y yang era suficiente explicación de cómo funcionaba o fallaba el cuerpo.

\section{Palabras Clave:}

Chakras, ayurved, seres divinos cuatro humores, bilis negra, bilis amarilla, sangre y flema, salud mental, yoga

\footnotetext{
a Escuela Superior Tepeji del Rio, Licenciatura Médico Cirujano, Universidad Autónoma del Estado de Hidalgo, Av. Del Maestro No. 41, Col. Noxtongo 2a Sección, Tepeji del Rio, Hidalgo, México, CP. 42855 Email: *stephanie.tapiap.14k@ gmail.com
} 


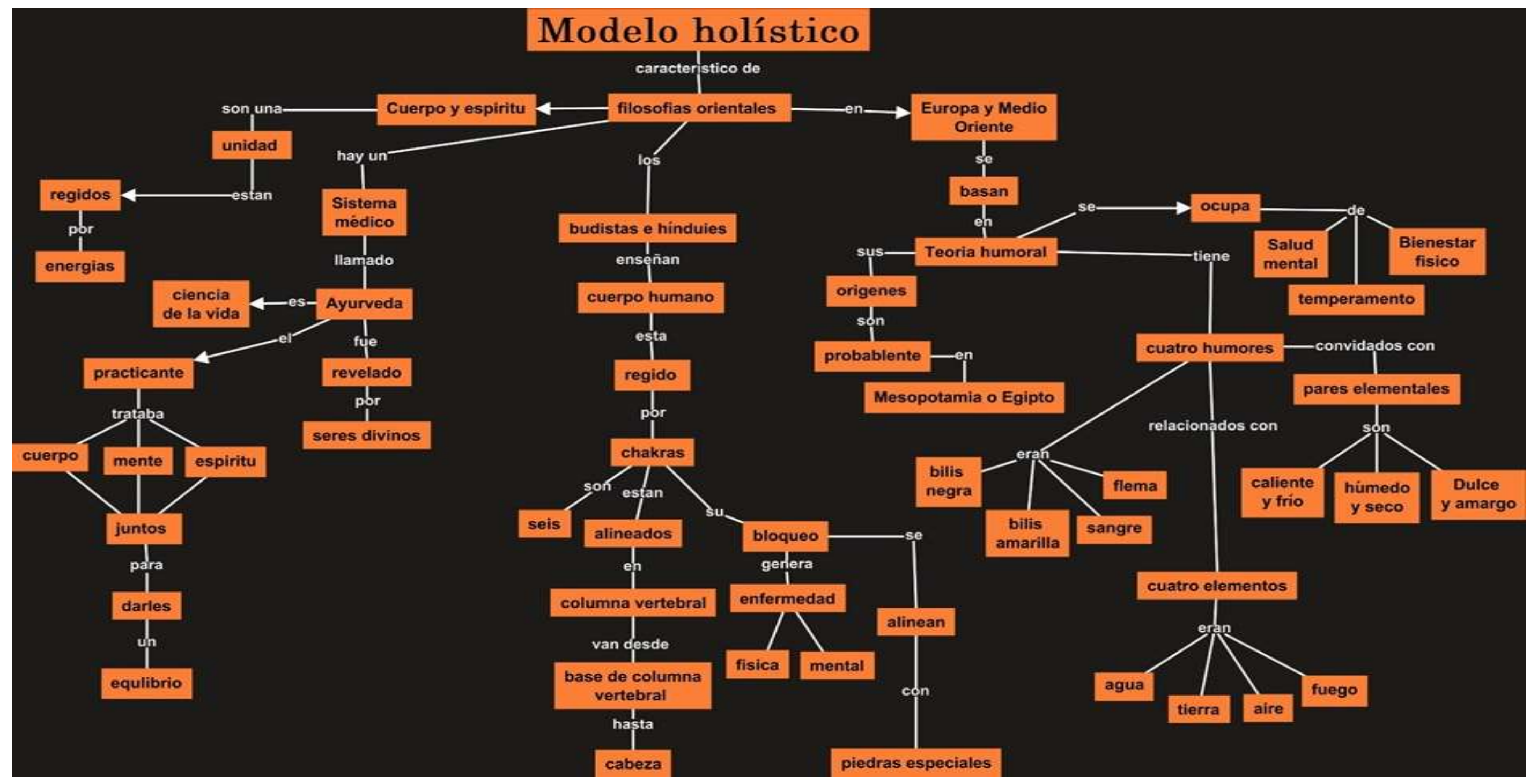




\section{Referencias}

[1] Rooney, A. (2013). La historia de la medicina. Grupo editorial Tomo.

[2] Foucault, Michel (1977). “Historia de la medicalización”, Educación médica y salud, Washington,11 (1)

[3] Hipócrates (1997). Juramento hipocrático, Tratados médicos, Barcelona: Planeta DeAgostini, 343 pp.

[4] Ackerknecht, Erwin (1986). La médecine hospitaliére á Paris. 1794-1848, Paris: Payot 